\title{
The Coaching Kaleidoscope: Insights from the Inside
}

Book Review

\author{
Author: Manfred Kets de Vries et al \\ Reviewed by: Shiva Kumar Srinivasan \\ Indian Institute of Planning and Management (IIPM), Chennai, India \\ shiva.srinivasan@iipm.edu
}

The Global Leadership Centre at INSEAD, Fontainebleau has become increasingly synonymous with executive and leadership coaching and is probably the most important brand in this area of management education. The person who made this possible is Manfred F. R. Kets de Vries who, in addition to developing the clinical paradigm in management education, has made the passion for developing people who in turn will develop people not only the mainstay of his work at INSEAD, but, of late, at ESMT, Berlin. This anthology of essays is a collaborative effort between Kets de Vries and his protégés at INSEAD and ESMT. They include Elizabeth Florent-Treacy at INSEAD, and Laura Guillen, and Konstantin Korotov at ESMT. While Kets de Vries and his associates have managed to produce not only a substantial but an increasingly influential literature on the clinical paradigm, readers encountering their work for the first time might want to consider beginning with this volume. Here, they will encounter the kaleidoscopic possibilities of coaching as a pragmatic endeavour, the meta-psychological and methodological considerations needed to legitimize it as an academic and consulting process, the 'who's who' of the coaching profession in Europe, and the important role that coaching plays in business schools in France and Germany. The term 'kaleidoscope' in Greek literally means 'watching beautiful forms'. These forms are generated by the optical construction of a kaleidoscope, which, on being rotated, produces an endless combination of aesthetic shapes and structures. The contributors to this volume believe that the formation of professional identity through executive and leadership is analogously akin to such forms.

The interventions made by an executive or leadership coach is synonymous with the process of rotating the kaleidoscope to generate forms of professional identity that are as bewitching as the 'combinatorial possibilities' inherent to the construction of this optical instrument. Not only is an infinite set of combinations possible, the coach can directly see the contributions that the process of coaching can make to the generation of these forms. It addresses therefore the coach's need to be generative vis-à-vis the formation of the next generation of executives. I am using the term 'generative' in the sense that the Harvard psychologist Erik Erikson meant by the notion of 'generatively'. In the Eriksonian schema of the developmental cycle, generatively is the opposite of 'stagnation'. What the coach's desire represents is not just the need to be generative in the personal sense of being a creative professional himself, but the need to actively participate in the process of generating professionals who are preoccupied with the fundamental questions of human development. Only doing this on a large scale will ensure that we can generate workforces that are sensitized as early as possible in their careers on the need to proactively shape workplaces that are creative in the holistic sense of the term rather than places from which workers leave every day with a sense of dire futility. The organizational ideal that Kets de Vries and the clinical paradigm are describing is called the 'authentizotic' organization. Here employees will have a much better understanding, respect, and affection for each other than is presently the case.

Readers may be tempted to quickly conclude that all this has been attempted before by the humanists whose ideals were subject to severe critique by the psychoanalyst themselves. Readers of a literary persuasion will recollect Lionel Trilling's arguments in favour of 'authenticity and sincerity' and note that while his arguments were ennobling, it did not lead to anything much even within literary criticism. Is not expecting executive coaches to bring about a whole-scale existential transformation of the corporate work place a bit too much to ask? Readers will also note that Trilling's work on humanism, for instance, did not square neatly with his own reading of Sigmund Freud (who partly because of his own war experiences in Europe) felt that there was something inherently self-destructive in human nature which he described as the 'death instinct'. This death instinct seems to work relentlessly against the best interests of both individuals and society, and is a force that coaches encounter all the time in the cases collected here and elsewhere though they may describe it in the language of 'self-disruption' rather than as a death instinct in the strong, clinical sense of the term. Executive coaching then despite its European origins and its interest in Freudian psychoanalysis is much more optimistic and melioristic in its 
theoretical orientation. It believes that the application of clinical insights will make possible in the symbolic construction of organizational life what Freud at times felt was not possible even within the space of the clinic(given the problematic nature of a 'cure' in psychoanalytic theory and practice). Whether this is because executive coaches tend to be upbeat in terms of their personality structure (unlike psychoanalysts who believed that the best psychoanalysis could do was to convert neurotic misery into common forms of unhappiness), or whether business communities are inherently more optimistic in the entrepreneurial sense of continually anticipating success is something that requires more thinking-through by theorists. Nonetheless what we have here is a great example of putting a clinical paradigm to work for what it is worth within the context of management education.

There is also the suggestion that is often made that executive coaching removes the 'stigma' of weakness from traditional forms of counselling and psychotherapy and brings about instead a heady melange of coaching, management education, and well-disguised psychotherapy. Another important thought that we might want to note in passing is that even in the Americas (North and South), there has always been a tradition of psychoanalysts who have spent a lot of time listening to the travails of the business community in silence without providing too much advice since that would sound like 'suggestion' (a practice that Freud frowned upon given its methodological link to hypnotism and mesmerism from which he felt that he had liberated psychoanalysis). What executive coaching does then is to say that if giving advice to the patient or the client is permissible, the coaching delimited to professional considerations without dragging in all the neuroses that afflict the client, and if the analyst were himself educated in the technical demands of the business to which the client belongs, and the labyrinths of organizational life, then, it might actually be possible to set up a thriving clinical practice (a goal that incidentally eludes many people with psychoanalytic training given their dependence on psychiatric referral centres for getting their share of patients). In executive coaching, there are no patients, only clients or coaches, no methodological strictures in excess or asymmetrical restraints on speech and interpretation like clinical psychoanalysis. Coaches can choose a variety of interventional methods using the range of cognitive tools used by coaches, consultants, management educators, leadership trainers, etc.

The invocation of the image of a kaleidoscope is not just a happy figure of speech for this anthology of essays. I think there are important methodological implications here that we might describe as 'different strokes for different folks' in terms of 'folk psychology'. I am certainly not implying that anything goes in terms of the methodology invoked in executive coaching - far from it. In fact, one of the reasons that Kets de Vries and his associates have put in so much laborious work is to prevent precisely that perception from taking root. What they prefer is methodological pluralism (compared to the more orthodox forms of psychoanalysis), but not an indifference to method. They are willing to experiment with a range of approaches from psychoanalysis, behavioural sciences, coaching protocols, psychodynamic approaches to counselling, family and marital therapy, systems analysis, etc., depending on the specifications of the client or the HR teams of the organizations that hire their services with an outcome and/or results-based preoccupation. That is probably the main theoretical difference between the clinical profession (which is preoccupied with methodological and meta-psychological questions) and the clinical paradigm in management education. Here there is a greater willingness to think back from a successful intervention to asking what sort of methodological considerations or assumptions must have been in place to explain the success of the intervention on the part of the coach as opposed to asking what must we suppose about the structure and function of the ontological or pre-ontological structure of the unconscious if we are to attempt a psychotherapeutic intervention of the sort that can be described as 'clinical'.

There are three parts to this book. The first part introduces the meta-psychological considerations and the techniques of analysis. It has discussions on where the clinical paradigm is coming from, what are its uses, cautionary notes on the range of acceptable behaviour for coaches, practical questions like how to identify and deploy transitional spaces and holding environments, and how the process of management education itself, including the coaching dimension, can be understood as a set of 'transitional phenomena' in the technical vocabulary of the British psychoanalyst, Donald W. Winnicot. The adequacy or inadequacy of coaching based interventions is also understood through the Winnicottian notion of the 'good enough mother'. This is an idea in Winnicot's work which helps those working in this clinical paradigm to make a transition from the tradition of mother-blaming that characterized oedipal configurations in Freudian psychoanalysis, to something that can, in fact, be attained if we invoke pragmatic criteria. Winnicot had argued - given his beginnings in paediatrics (as opposed to psychoanalysis) - that it will suffice to invoke a notion of 'good-enough' mothering as opposed to perfect mothering. 
Winnicot encountered in his clinical practice a large number of women who blamed themselves for all the problems that afflicted their children without realizing that they were unconsciously setting themselves up for failure as a parent. Instead, Winnicot argued that a more pragmatic approach might be to encourage mothers to be not only reasonable in their approach to child rearing, but to resist the temptation of flagellating themselves for everything that might go wrong. Winnicot's notion of the 'good enough mother' is to parenting, I am tempted to point out, what the notion of 'satisficing' is to decision making in the work of Herbert Simon. In fact, this analogue is what makes it easier for a coach to make a successful transition to working with an outcomes based approach as opposed to starting with too many worries about methodology. A great deal of methodology then in executive coaching is retroactively constructed and then proactively applied in assignments that bear an analogy to past experience. The second part comprises a number of cases and coaching memoirs that bring to light some of these problems.

The third and final part is an attempt to pick up different aspects of coaching with a range of assignments, clients, and goals in mind. So, for instance, how will what has been learnt so far help coaches to be more effective in designing better places to work? This is an important consideration given that the rankings of workplaces and determining the criteria that should be applied to these rankings can become a huge obsession for those in the business media and in the behavioural sciences. What are the criteria that Kets de Vries and his associates have in mind for identifying and designing authentizotic organizations with or without actual examples in mind? Additional questions relate to how coaching practices can help to improve the construction of teams and the quality of team work. The challenge of developing teams of various sorts depending upon the specifications of a variety of firms, organizations, and sectors is going to keep coaches busy in the years to come. The third part also tries to explain how the clinical paradigm is related to the systems view of organizations, and tries to demonstrate when and how, say, an organizational development consultant might want to apply the clinical approach or integrate it with the systems approach. Further uses of coaching stem from the need to prepare a workforce that is able to come to terms with the requirements of a family business, understand the emerging demands of a new generation which has a much greater commitment to questions of work-life balance, and the problem of understanding cultural differences to the extent that is necessary in both multicultural environments and multinational organizations. The main takeaway here is not that employees can't learn or find a way on their own, but rather that the formal provision of 'holding environments' will not only make the process of organizational learning more enjoyable, but make employees more creative, decisive, and reflective in their attempts to attain wisdom at work. 